\title{
Correction to: Description of a new needle nematode, Paralongidorus koreanensis n. sp., and two known Xiphinema spp. cobb, 1913, from turfgrass in Korea
}

\author{
Abraham Okki Mwamula • Wilfrida Decraemer • \\ Yeong Ho Kim • Hyoung-Rai Ko • Heebeen Na • \\ Young Ho Kim • Dong Woon Lee 1
}

Published online: 20 January 2020

(C) Koninklijke Nederlandse Planteziektenkundige Vereniging 2020

\author{
Correction to: Eur J Plant Pathol \\ https://doi.org/10.1007/s10658-019-01846-4
}

This erratum has been created as many author corrections were overlooked in proofing stage.

The online version of the original article can be found at https://doi.org/10.1007/s10658-019-01846-4

A. O. Mwamula $\cdot$ H. Na $\cdot$ D. W. Lee $(\bowtie)$

Department of Ecological Science, Kyungpook National University, Sangju 37224, South Korea

e-mail: whitegrub@knu.ac.kr

A. O. Mwamula

Department of Zoology, Entomology and Fisheries Sciences,

College of Natural Sciences, Makerere University, Kampala 7062,

Uganda

W. Decraemer

Department of Biology, Ghent University, K.L. Ledeganckstraat

35, 9000 Ghent, Belgium

Y. H. Kim • Y. H. Kim

School of Ecological Environment and Tourism, Kyungpook

National University, Sangju 37224, South Korea

H.-R. Ko

Crop Protection Division, National Institute of Agricultural Science, Rural Development Administration, Wanju 55365, South Korea 